\title{
Corium molecular biomarkers reveal a beneficial effect on hoof transcriptomics in peripartal dairy cows supplemented with zinc, manganese, and copper from amino acid complexes and cobalt from cobalt glucoheptonate
}

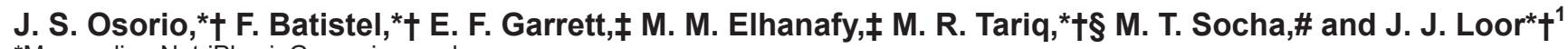 \\ *Mammalian NutriPhysioGenomics, and \\ †Department of Animal Sciences and Division of Nutritional Sciences, University of Illinois, 1207 West Gregory Drive, Urbana 61801 \\ ‡Department of Veterinary Clinical Medicine, University of Illinois, 1008 W. Hazelwood Drive, Urbana 61802 \\ §Department of Food Science and Technology, University College of Agriculture and Environmental Sciences, \\ The Islamia University of Bahawalpur, Punjab 62300, Pakistan \\ \#Zinpro Corporation, Eden Prairie, MN 55344
}

\begin{abstract}
Supplying trace minerals in more bioavailable forms such as amino acid complexes (AAC) could help ameliorate the incidence of hoof disorders in peripartal dairy cows. The aim of this study was to evaluate the effects of supplementing metal AAC during the peripartal period on expression of 28 genes in corium tissue related to claw composition, oxidative stress, inflammation, chemotaxis, and transcriptional regulation. Forty-four multiparous Holstein cows received a common diet from -30 to $30 \mathrm{~d}$ relative to parturition and were assigned to receive an oral bolus containing either inorganic trace minerals (INO) or AAC (i.e., organic) $\mathrm{Zn}, \mathrm{Mn}, \mathrm{Cu}$, and Co to achieve supplemental levels of $75,65,11$, and 1 ppm, respectively, in the total diet dry matter. Inorganic trace minerals were provided in sulfate form, and AAC were supplied via Availa Zn, Availa Mn, Availa $\mathrm{Cu}$, and COPRO (Zinpro Corp., Eden Prairie, MN). Locomotion score was recorded before enrollment and weekly throughout the experiment. Incidence of hoof health problems at $30 \mathrm{~d}$ in milk was evaluated before a hoof biopsy in a subset of cows $(\mathrm{INO}=10 ; \mathrm{AAC}=$ 9). Locomotion score did not differ between treatments in the prepartum or postpartum period. The incidence of heel horn erosion was lower in AAC cows, but the incidence of sole ulcers did not differ. Downregulation of KRT5, CTH, CALML5, and $C Y B B$, and upregulation of $B T D$ in AAC cows indicated a decrease in the need for activation of cellular pathways to regenerate corium tissue and increase biotin availability in the sole claw. These molecular changes in the sole could have been triggered by the lower incidence of heel erosion in response to AAC. Among the genes associated with
\end{abstract}

Received November 30, 2015

Accepted August 30, 2016.

${ }^{1}$ Corresponding author: jloor@illinois.edu oxidative stress, the AAC cows had greater expression of NFE2L2, a transcription factor that regulates the antioxidant response, and the antioxidant enzyme SOD1. Among genes associated with inflammation, AAC cows had greater expression of TLR4, and lower expression of TLR2, IL1B, and TNF compared with INO cows. Supplementation with metal AAC during the peripartal period affected the expression of genes involved in composition, oxidative stress, and inflammation status in the corium. The hoof biopsy procedure used in the present study should be further perfected and implemented in future lameness research to expand our understanding of hoof biology in dairy cows.

Key words: organic minerals, dairy cattle, transition period, gene expression

\section{INTRODUCTION}

Lameness is of great interest to the dairy industry because of its economic impact and effect on animal welfare (Cha et al., 2010; Shearer et al., 2013). Important trace minerals such as $\mathrm{Zn}, \mathrm{Mn}$, and $\mathrm{Cu}$ are essential cofactors for multiple enzymes including those involved in keratin formation; therefore, these trace minerals have been associated with hoof health (Tomlinson et al., 2004). The low DMI of early postpartal dairy cows relative to the large requirements for milk production compromises supply of most nutrients including trace minerals. In addition, negative interactions among trace minerals and macrominerals and dietary factors pre and post absorption can further reduce trace mineral bioavailability (NRC, 2001). Therefore, the use of organic forms [e.g., complexed, covalently bonded to AA; amino acid complex (AAC)] of these trace minerals has been widely adopted by the dairy industry.

We have successfully demonstrated the feasibility of performing a hoof biopsy in dry, nonpregnant dairy cows with the aim of isolating mRNA from corium tis- 
sue to perform gene expression analyses, minimizing adverse effects on locomotion score and overall hoof health (Osorio et al., 2012). The use of this procedure allows for the in vivo study of important biological processes in the corium tissue, including keratinization, inflammation, and oxidative stress.

Keratinization of the bovine hoof is a complex and dynamic process that responds to stimuli (e.g., mechanical damage, trace minerals imbalance, inflammation) to maintain the strength and integrity of the hoof capsule (Hendry et al., 1997; Tomlinson et al., 2004). Among several keratins we evaluated for keratinization, KRT5 was the most important at a transcriptional level in immature keratinocytes (Osorio et al., 2012). Biotin is an important vitamin for keratinization and hoof integrity (Tomlinson et al., 2004), underscoring the importance of biotinidase (encoded by BTD), an enzyme responsible for the use and recycling of biotin.

Based on previous corium transcriptomic data between susceptible and non-susceptible claws from dry nonpregnant cows (Osorio et al., 2012), we hypothesized that genes associated with keratinization, such as KRT5 and $B T D$, would be affected by the supply and source of trace minerals. Furthermore, we hypothesized that proinflammatory genes would be downregulated with AAC supplementation. The proinflammatory response can be initiated via different pathways, including the toll-like receptors (TLR; e.g., TLR2 and TLR4), which are perhaps the most widely studied. Upon activation of the TLR pathway, the primary outcome is the synthesis of proinflammatory cytokines (e.g., tumor necrosis factor, TNF, IL-1 , and IL-6; De Nardo, 2015). Activation of proinflammatory cytokines can upregulate matrix metalloproteinases that have collagenase activity and impair the integrity of the suspensory apparatus of the hoof capsule (Dufour, 2015). The objective of this study was to evaluate the effects of supplementing AAC during the peripartal period on genes related to claw composition, oxidative stress, inflammation, chemotaxis, and transcriptional regulation.

\section{MATERIALS AND METHODS}

\section{Experimental Design and Dietary Treatments}

The Institutional Animal Care and Use Committee of the University of Illinois approved all protocols for this study (protocol no. 12097). The experiment was conducted as a randomized complete block design where 44 multiparous Holstein cows were blocked according to parity, previous lactation milk yield, and expected day of calving (Osorio et al., 2016). The complete description of the experimental design is reported elsewhere (Osorio et al., 2016). Briefly, cows received a common diet supplemented at $100 \%$ of NRC (2001) requirements with $\mathrm{Zn}, \mathrm{Mn}, \mathrm{Cu}$, and $\mathrm{Co}$ in the form of inorganic trace minerals (INO) from 110 to $30 \mathrm{~d}$ before calving. From $-30 \mathrm{~d}$ to calving, cows received a common prepartal diet (1.5 Mcal/kg of DM, $15 \% \mathrm{CP})$, and from calving to $30 \mathrm{DIM}$ a common postpartal diet (1.76 $\mathrm{Mcal} / \mathrm{kg}$ of DM, $18 \% \mathrm{CP}$ ). Both diets were partially supplemented with an INO mix of $\mathrm{Zn}, \mathrm{Mn}$, and $\mathrm{Cu}$ to supply 35, 45, and $6 \mathrm{ppm}$, respectively, of the total diet DM. Cows were assigned to treatments in a randomized completed block design, receiving a daily oral bolus with a mix of INO or AAC containing 40,20,5, and $1 \mathrm{ppm}$ of $\mathrm{Zn}, \mathrm{Mn}, \mathrm{Cu}$, and $\mathrm{Co}$, respectively, to achieve $75,65,11$, and $1 \mathrm{ppm}$, respectively, in the total diet DM. Inorganic trace minerals were provided in sulfate form and AAC were supplied as Availa Zn, Availa Mn, Availa $\mathrm{Cu}$, and COPRO (Zinpro Corp., Eden Prairie, $\mathrm{MN})$. As described in Osorio et al. (2016) and Batistel et al. (2016), some cows were removed during the experiment due to health complications; none of those cows were included in the present analysis. Per Institutional Animal Care and Use Committee guidelines, 12 cows per treatment were approved for liver biopsies, corium biopsies, blood neutrophil RNA isolation, and blood biomarker analysis. However, from these subsets, only 10 INO and 9 AAC cows had a corium biopsy plus a complete set of liver biopsies, neutrophil RNA, and corresponding blood samples; only these cows were used for the corium mRNA expression analysis.

\section{Animal Management and Locomotion Score}

Prior to calving, cows were fed individually once daily at $0630 \mathrm{~h}$ using an individual gate system (American Calan, Northwood, NH). Cows were housed on concrete floors in a ventilated enclosed barn during the dry period and had access to sand-bedded free stalls until $3 \mathrm{~d}$ before expected parturition, when they were moved to individual maternity pens bedded with straw until parturition. After parturition, cows were housed in a tie-stall barn, fed a common lactation diet once daily, and milked 3 times daily. At 30 DIM, cows were returned to the farm herd. Feed offered was adjusted daily to achieve 5 to $10 \%$ refusals.

A locomotion score was assigned by 2 individuals before cows were enrolled in the experiment, based on a scale described by Flower and Weary $(2006 ; 1=$ normal, symmetrical gait and flat back to $5=$ lame, asymmetric gait, extremely arched back) to discriminate cows with mild to severe lameness $(>2)$. The same 2 individuals recorded weekly locomotion scores for all cows in the experiment, including those that were not used for hoof biopsies [INO $=21$ and $\mathrm{AAC}=16$ as in Osorio et al. (2016)], from -30 to $30 \mathrm{~d}$ relative to par- 
Table 1. Frequency of occurrence of hoof health problems ${ }^{1}$ at 30 DIM in cows supplemented with inorganic (INO) or metal amino acid complex (AAC) trace minerals during the peripartal period

\begin{tabular}{lccc}
\hline & \multicolumn{2}{c}{ Treatment } & \\
\cline { 2 - 3 } Variable & INO & AAC & P-value \\
\hline Number of cows & 10 & 9 & \\
White line & 4 & 4 & 1.0 \\
Sole hemorrhage & 1 & 2 & 0.58 \\
Heel horn erosion & 8 & 3 & 0.07 \\
Digital dermatitis & 3 & 2 & 1.0 \\
\hline
\end{tabular}

${ }^{1}$ Hoof evaluations were made on the right rear medial and lateral claws at $30 \mathrm{~d}$ postpartum and before the hoof biopsy. Hoof health disease or disorder was considered if at least mild.

turition. A final average locomotion score was used for statistical analysis. Prior to enrollment, all cows were inspected and trimmed by a professional trimmer to look for possible visual signs of hoof disease (e.g., sole ulcers, white line). Similarly, claws in the right rear hoof were inspected by a veterinarian at 30 DIM before the hoof biopsy, and observations are reported in Table 1. No hoof examinations were performed in other cows in the experiment.

\section{Hoof Samples}

Hoof biopsy was performed at 30 DIM according to our published procedure (Osorio et al., 2012), with a few modifications. Briefly, the lateral claw of the lower right hind limb (e.g., right rear) was cleaned with povidone iodine scrub (Cat\# 25655-41-8; Durvet Inc., Blue Springs, MO), allowing 3 min of contact time. All biopsy instruments remained in an antiseptic solution until use. A tourniquet was applied midway between the fetlock and tarsus/carpus. Local anesthesia was accomplished using a regional block of the digital nerves using $5 \mathrm{~mL}$ of $2 \%$ lidocaine- $\mathrm{HCl}$ (Agri Laboratories, St. Joseph, MO).

After confirmation that anesthesia was successful, the sole of the hoof was perforated in claw zone 4 (Vermunt and Greenough, 1996) using a $12 \mathrm{~mm}$ drill bit. The hoof horn overlying the biopsy site was removed with the drill bit until 1 to $2 \mathrm{~mm}$ of hoof wall remained. The optimal depth was assessed by the change in ease of passage of the drill bit through the hoof and by resistance of the hoof horn to pressure. The tissue specimen was obtained using a $6 \mathrm{~mm}$ biopsy punch (Cat\# HLBP99; MedExSupply, Monsey, NY) inserted through the hole and used to cut through the remaining hoof wall and the underlying corium. Sterile gauze was applied to the biopsy site and held in place with tape. A wooden hoof block (Cat\# 46131; Bovi-Bond, Oxnard, CA) was affixed with epoxy (Cat\# 46130; Bovi-Bond) on the medial claw from the same limb where the bi- opsy was performed to relieve weight bearing on the claw from which the biopsy was taken. Biopsy samples were cleaned with dry gauze and stored in liquid $\mathrm{N}_{2}$ until RNA extraction.

\section{RNA Extraction, Quantitative qPCR, and Design and Evaluation of Primers}

Total RNA was extracted from hoof samples using established protocols in our laboratory (see supplemental materials for details: http://dx.doi.org/10.3168/ jds.2015-10698). Details of quantitative PCR, design, and primer evaluation are also presented in the supplementary materials. The selected target genes (Table 2) play important roles in claw composition (i.e., KRT5, $B T D, P K C D, V E G F A, C A L M L 5, A L P$, and $C T H)$, oxidative stress (i.e., SOD1, SOD2, SOD3, GPX1, and NFE2L2), chemotaxis (i.e., LTA $4 H$ and IL8), inflammation (i.e., TLR4, TLR2, MYD88, NFKB1, TNF, IL6, STAT3, SAA3, CYBB, and IL1B), and transcription regulation (i.e., RXRA, PPARA, PPARD, $P P A R G)$. Further information regarding these targets genes is presented in Supplemental Table S1 (http:// dx.doi.org/10.3168/jds.2015-10698). For this study, $G A P D H, R P S 9$, and UXT were used as internal control genes (Osorio et al., 2012). The geometric mean of the internal control genes was used to normalize the expression data and generate a percentage relative abundance of mRNA (Supplemental Table S2; http:// dx.doi.org/10.3168/jds.2015-10698) and provide additional mechanistic information on the target genes. The stability of the normalization factor was assessed using geNorm software (Vandesompele et al., 2002) with a favorable final pairwise variation of 0.18 .

\section{Statistical Analysis}

The gene expression data were log-transformed before statistical analysis using the PROC MIXED procedure in SAS 9.3 (SAS Institute Inc., Cary, NC). The gene expression analysis included diet as a fixed effect and cow as a random effect. In the case of locomotion score, we included time as a fixed effect and the interaction of diet $\times$ time. The results of the hoof evaluation performed at 30 DIM were analyzed using a Fisher exact test and PROC FREQ in SAS. Statistical significance was declared at $P \leq 0.05$, and tendencies at $P \leq 0.15$.

\section{RESULTS}

\section{Locomotion Score}

Among the cows used during the experiment, only 2 in each treatment were diagnosed as mildly lame (e.g., 2 on the scale of $1-5$ ), and the rest were normal (score 
of 1.0). The mildly lame cows were not used for gene expression analysis. Overall, the average locomotion score was 1.11 in INO cows and $1.07 \pm 0.05$ in AAC cows prepartum, and 1.35 in INO cows and $1.11 \pm 0.15$ in AAC cows postpartum. We observed no effect $(P$ $>0.27)$ of diet, time, or diet $\times$ time in locomotion score during the prepartal or postpartal stage (data not shown). Although the incidence of white line disease, sole hemorrhage, and digital dermatitis did not differ $(P \geq 0.58)$ at 30 DIM, we observed a strong tendency $(P=0.07)$ for greater incidence of heel horn erosion in INO cows (Table 1$)$.

Table 2. Symbol, name, and main biological function or process of genes analyzed

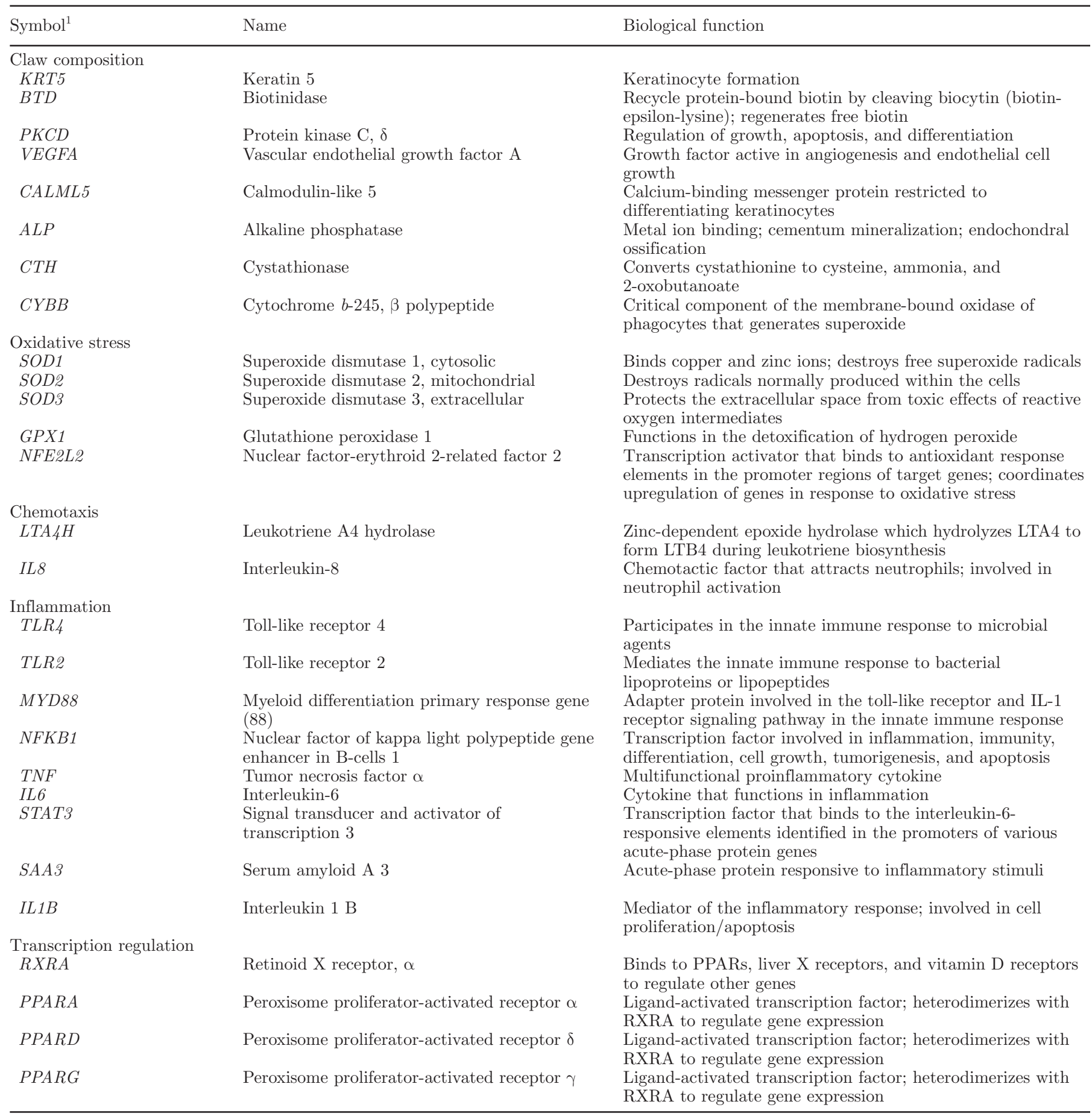

\footnotetext{
${ }^{1}$ Entrez Gene; National Center for Biotechnology Information.
} 
OSORIO ET AL.

Table 3. Messenger RNA expression of genes in hoof tissue on d 30 postpartum

\begin{tabular}{|c|c|c|c|c|}
\hline \multirow[b]{2}{*}{ Gene } & \multicolumn{2}{|c|}{ Treatment $^{1}$} & \multirow[b]{2}{*}{ SEM } & \multirow[b]{2}{*}{ Diet } \\
\hline & INO & $\mathrm{AAC}$ & & \\
\hline \multicolumn{5}{|c|}{ Claw composition } \\
\hline KRT5 & 5.32 & 2.79 & 0.58 & $<0.01$ \\
\hline$B T D$ & 4.67 & 5.71 & 0.20 & $<0.01$ \\
\hline$P K C D$ & 5.16 & 5.13 & 0.15 & 0.89 \\
\hline$V E G F A$ & 5.60 & 5.22 & 0.18 & 0.15 \\
\hline CALML5 & 5.45 & 4.86 & 0.19 & 0.04 \\
\hline$A L P$ & 5.76 & 5.73 & 0.20 & 0.92 \\
\hline $\mathrm{CTH}$ & 5.19 & 4.24 & 0.23 & 0.01 \\
\hline$C Y B B$ & 5.51 & 4.61 & 0.31 & 0.05 \\
\hline \multicolumn{5}{|c|}{ Oxidative stress } \\
\hline SOD1 & 5.43 & 5.67 & 0.08 & 0.06 \\
\hline SOD2 & 5.59 & 5.30 & 0.10 & 0.06 \\
\hline SOD3 & 5.15 & 5.21 & 0.41 & 0.92 \\
\hline$G P X 1$ & 5.75 & 5.17 & 0.17 & 0.03 \\
\hline NFE2L2 & 5.29 & 5.79 & 0.13 & 0.01 \\
\hline \multicolumn{5}{|l|}{ Chemotaxis } \\
\hline IL 8 & 5.03 & 4.46 & 0.52 & 0.44 \\
\hline $\mathrm{LTA}_{4} \mathrm{H}$ & 5.51 & 5.64 & 0.06 & 0.13 \\
\hline \multicolumn{5}{|c|}{ Inflammation } \\
\hline TLR2 & 5.82 & 4.99 & 0.30 & 0.02 \\
\hline TLR4 & 5.23 & 6.00 & 0.17 & $<0.01$ \\
\hline$M Y D 88$ & 5.58 & 5.56 & 0.09 & 0.88 \\
\hline$N F K B 1$ & 5.49 & 5.44 & 0.07 & 0.60 \\
\hline$T N F$ & 5.47 & 3.90 & 0.51 & 0.04 \\
\hline IL 6 & 5.36 & 5.39 & 0.23 & 0.92 \\
\hline SAA3 & 5.20 & 4.17 & 0.54 & 0.17 \\
\hline STAT3 & 5.45 & 5.45 & 0.11 & 0.98 \\
\hline$I L 1 B$ & 5.77 & 4.58 & 0.43 & 0.06 \\
\hline \multicolumn{5}{|c|}{ Transcription factors } \\
\hline$R X R A$ & 5.42 & 5.58 & 0.09 & 0.21 \\
\hline PPARA & 5.51 & 5.87 & 0.12 & 0.04 \\
\hline$P P A R G$ & 3.85 & 3.80 & 0.18 & 0.84 \\
\hline PPARD & 5.24 & 5.65 & 0.10 & 0.01 \\
\hline
\end{tabular}

${ }^{1}$ Cows were fed a basal diet supplemented with inorganic (INO) or metal amino acid complex (AAC) trace minerals during the peripartal period.

\section{Gene Expression}

Claw Composition. Among the genes associated with claw composition, the expression of KRT5 ( $P$ $<0.01), C T H(P=0.01), C A L M L 5(P=0.04)$, and $C Y B B(P=0.05)$ was downregulated in AAC cows compared with INO cows (Table 3 ). In contrast, BTD was upregulated $(P<0.01)$ in AAC cows. We observed a trend $(P=0.15)$ for lower expression of $V E G F A$ in AAC cows. The mRNA expression of $A L P(P=0.92)$ and $P K C D(P=0.89)$ was not affected by dietary treatment.

Oxidative Stress. We observed greater $(P=0.01)$ expression of NFE2L2 in AAC cows compared with INO cows, but GPX1 was lower $(P=0.03)$ in AAC cows. Expression of $S O D 1$ tended $(P=0.06)$ to be higher and expression of SOD2 tended to be lower ( $P$ $=0.06)$ in AAC cows. Expression of SOD3 was not affected $(P=0.92)$ by dietary treatments.
Chemotaxis. We observed a trend $(P=0.13)$ for greater expression of $L T A 4 H$ in AAC cows compared with INO cows, but $I L 8$ was not affected $(P=0.44)$ by dietary treatments.

Inflammation. We observed a greater $(P<0.01)$ expression of TLR4 in AAC cows compared with INO cows. In contrast to TLR 4, the expression of TLR2 ( $P$ $=0.02)$ and $\operatorname{TNF}(P=0.04)$ was downregulated in AAC cows. We observed a trend $(P=0.06)$ for $I L 1 B$ because of lower expression in AAC cows. The remaining genes evaluated (MYD88, NFBK1,IL6, SAA3, and STAT3) were not affected (all $P>0.17$ ) by dietary treatment.

Transcription Factors. Among the transcription factors evaluated, only PPARA $(P=0.04)$ and PPARD $(P=0.01)$ were affected by diet; both genes were upregulated in AAC cows compared with INO cows. In contrast, PPARG $(P=0.84)$ and $R X R A(P=0.21)$ were not affected by diet. 


\section{DISCUSSION}

Supplementing lactating dairy cows with AAC has been positively associated with improved milk yield and reproductive performance (Rabiee et al., 2010), as well as decreased SCC (Kellogg et al., 2004). Similarly, production and biomarker data from cows in this study indicated that supplementing peripartal dairy cows with AAC could minimize postpartal liver damage and the risk of developing ketosis while at the same time promoting increased DMI and milk yield (Osorio et al., 2016).

\section{Locomotion Score}

Lameness in dairy cows is of great interest to the dairy industry because of its economic impact and effect on animal welfare (Cha et al., 2010; Shearer et al., 2013). Trace minerals such as $\mathrm{Zn}, \mathrm{Mn}$, and $\mathrm{Cu}$ are essential cofactors for multiple enzymes, including those involved in keratin formation. Therefore, these trace minerals have been associated with hoof health (Tomlinson et al., 2004). In fact, hair and hoof samples from lame cows (locomotion score 3-5) had lower concentrations of these trace minerals compared with samples from healthy cows (locomotion score 1-2; Zhao et al., 2015b). Because lameness is a process that can develop at different rates depending on the underlying pathology, the absence of differences in locomotion score might not necessarily indicate that AAC and INO cows had a similar supply of trace minerals. Karkoodi et al. (2012) did not detect differences in locomotion score in peripartal cows fed diets supplemented with inorganic trace minerals (control), 25\% organic: $75 \%$ inorganic, and 50\% organic:50\% inorganic forms of $\mathrm{Zn}$, $\mathrm{Mn}, \mathrm{Cu}$, and Se from -21 to 90 DIM. This indicates that, if nutritionally driven, lameness is the ultimate consequence of a long-term condition (e.g., limited supply of trace minerals or rumen acidosis), and locomotion score might not be suitable for determining short-term trace mineral imbalance. In fact, long-term (i.e., from prepartum to >200 DIM) beneficial effects of feeding trace minerals on the hoof health of dairy cows have been reported previously (Ballantine et al., 2002; Siciliano-Jones et al., 2008), so it is likely that the duration of the present study was insufficient to detect differences in lameness.

\section{Genes Related to Claw Composition}

Keratinization of the bovine hoof is a complex and dynamic process that responds to stimuli (e.g., mechanical damage, trace minerals imbalance, inflamma- tion) to maintain the strength and integrity of the hoof capsule (Hendry et al., 1997; Tomlinson et al., 2004). Hendry et al. (2001) detected an increase in protein synthesis (including keratins) and cellular proliferation in ulcerated claws, indicating that this condition stimulated cellular repair. Although overall keratin 5 (KRT5) protein abundance did not differ between healthy and ulcerated bovine claws, they observed a significant presence of KRT5 in basal and supra-basal layers in necrotic tissues instead of basal layers only, as is commonly observed in healthy tissue, where keratinization initiates (Hendry et al., 2001). These results indicated that tissue damage results in an abnormal distribution of cytokeratins throughout the layers of the corium. We hypothesized that the greater KRT5 mRNA expression in INO cows could have been triggered by epidermal-dermal disturbances originated in the heel bulb. Whether the greater KRT5 mRNA expression was associated with the initial stages of a subclinical sole ulcer remains to be determined in future studies.

We hypothesized that the increase in protein synthesis (particularly of keratin proteins) and cellular proliferation reported by Hendry et al. (2001) in ulcerated hoof tissue might be preceded by an upregulation at the transcriptome level of keratins such as KRT5, and we observed this in the present study. Such an idea agrees with corium gene expression analysis (Osorio et al., 2012) between laminitis-susceptible (claw 5) and non-susceptible (claw 7) claws, where KRT5 was upregulated in susceptible claws. In fact, the relevance of changes in expression of keratins at the transcriptome level was underscored by the greater relative mRNA abundance of KRT5 among all genes evaluated in the present study (Supplemental Table S2; http://dx.doi. org/10.3168/jds.2015-10698).

Another potential explanation for the effect on KRT5 expression involves the activation of IL1 $\beta$ in keratinocytes that in turn could stimulate nearby fibroblasts to secrete growth factors and cytokines, such as keratinocyte growth factor (KGF), IL-6, and colony-stimulating factor 2 (Waelti et al., 1992; Boxman et al., 1996). Although the latter has been mainly detected in vitro and the population of fibroblasts was not determined in the present study, it represents an alternative mechanism by which keratinocytes can regulate their own proliferation and differentiation via the IL1 $\beta$-fibroblast-KGF axis (Arai et al., 2014). Therefore, upregulation of $I L 1 B$ in INO cows might have induced a dual effect, stimulating an inflammatory response and inducing keratinocyte proliferation and differentiation reflected in the upregulation of KRT5. It is noteworthy that blood concentration of IL- 6 was greater after calving in INO than in AAC cows (Batistel et al., 2016), in line with 
the proposed mechanism in the hoof. Therefore, it is conceivable that heel erosion in INO cows might have triggered the above mechanism.

Although $C T H$ and $C A L M L 5$ encode for proteins that participate in different biological processes, they have been associated with keratinization (Méhul et al., 2001; Tomlinson et al., 2004). Cystathionine gammalyase (encoded by $\mathrm{CTH}$ ) is responsible for converting cystathione derived from Met into Cys, an important sulfur-containing amino acid essential for proper keratin protein structure (Tomlinson et al., 2004). Keratin differentiation is partly a calcium-dependent process (Hennings et al., 1980) that can be stimulated by calcium carriers such as calmodulin-like protein (encoded by CALML5; Méhul et al., 2001). Coupled with the upregulation of KRT5 in INO cows, the above mechanism by which keratinization is stimulated during high demand for tissue repair is in agreement with the upregulation of genes associated with keratinization (i.e., $C T H$ and CALML5). Whether the origin of such an effect was the increase in incidence of heel erosion could not be assessed in the present study. Future research should be conducted to clarify such effects and understand the extent to which the severity of an adjacent hoof disease can modify molecular pathways across other claw zones.

Biotin is a water-soluble B vitamin and possibly the most important vitamin for keratinization and maintenance of hoof integrity (Tomlinson et al., 2004). The latter is perhaps the most interesting characteristic of biotin: this vitamin is an essential cofactor of several enzymes directly related to the synthesis of lipids and glucose, with particular importance in the synthesis of long-chain fatty acids (Weiss and Zimmerly, 2000). In fact, Mülling et al. (1999) observed that biotin is essential for the synthesis of complex lipid molecules in the intercellular cementing substance, an essential extracellular matrix material critical for gluing together keratinocytes in the latter steps of keratinization or cornification. Therefore, the need for biotin for adequate synthesis of intercellular cementing substance gives this vitamin its beneficial effects for hoof integrity.

Dietary supplementation of biotin has been observed to increase both hoof growth rate and resistance to hoof pathologies (Bergsten et al., 2003; da Silva et al., 2010). Our results indicate that biotinidase (encoded by $B T D$ ), an enzyme responsible for the use and recycling of biotin, was upregulated in AAC cows compared with INO cows. As a result, the hoof integrity of AAC cows might have been less compromised than that of INO cows, requiring less cellular repair, and this finding is in agreement with the downregulation of KRT5 found in AAC cows. Although the origin of this effect in AAC cows could not be ascertained in the present study (e.g., indirectly through reduced heel erosion), the present data provide evidence that supplementation of AAC during the transition period has an effect on the hoof transcriptome. Clearly, further experiments including both protein and gene expression (particularly BTD and KRT5) should be conducted to confirm the absence of post-transcriptional regulation of these genes.

\section{Gene Related to Oxidative Stress}

Oxidative stress is driven by an imbalance between the production of reactive oxygen metabolites (ROM) and the neutralizing capacity of antioxidant mechanisms in tissues and blood. Although ROM production is an essential component of the host response to invading pathogens and traumas, it is harmful if not neutralized by antioxidant substances. Enhanced levels of ROM lead to oxidative stress, which has been implicated in the pathogenesis of a large number of metabolic disorders during the transition period (Abuelo et al., 2015) and seems to be related to the occurrence of lameness (Zhao et al., 2015b).

Among the well-known antioxidants are glutathione, superoxide dismutase (SOD), and vitamins A and E (Margaritelis et al., 2015). The 3 isoforms of SOD (SOD1, SOD2, and SOD3) are not only compartmentalized at the cellular level (i.e., cytoplasm, mitochondria, and extracellular, respectively) but also differ in that SOD1 and SOD3 require $\mathrm{Cu} / \mathrm{Zn}$ to be functional, and SOD2 requires Mn. The transcriptional response of SOD2 indicates that AAC cows had a lower demand for neutralizing reactive oxygen species at the mitochondrial level than in the cytoplasm. Evidence from mouse explants and cell culture shows that TNF can selectively induce SOD2 mRNA expression but not SOD1 (Matés, 2000), which is in agreement with the simultaneous upregulation of TNF and SOD2 detected in the current study.

Nuclear erythroid 2-related factor (NFE2L2) regulates the expression of several antioxidant enzymes, such as glutathione and SOD, via the antioxidant response element (ARE), which confers on this transcription factor a major role in the defense against ROM damage (Kansanen et al., 2013; Pillay et al., 2015). It is noteworthy that $\mathrm{Zn}$ has been associated with the activation of the NFE2L2-ARE pathway. For instance, Wang et al. (2015) detected greater protein and gene expression of Nfe2l2 in the liver of mice fed diets supplemented with Zn and subjected to heat stress. Therefore, greater bioavailability of $\mathrm{Zn}$ in AAC cows could partly explain the upregulation of NEF2L2. Although NFE2L2 was upregulated in AAC cows, this effect was not translated into upregulation of either SOD2 or GPX1. The 
antioxidant effects of NFE2L2 might be regulated at a post-transcriptional step because Kelch-like ECHassociated protein, an NFE2L2 inhibitor, can sequester and tag NFE2L2 for proteasomal degradation (Giudice et al., 2010). Therefore, greater expression of SOD2 and $G P X 1$ in INO cows could be more related to protein activity/availability of NFE2L2 than transcription.

The changes in expression of oxidative stress-related genes at the level of hoof tissue agree with the systemic biomarkers measured in these cows (Batistel et al., 2016). Clearly, these systemic and local events could increase the susceptibility of the cows to develop lameness (Zhao et al., 2015a). More research is needed to determine the extent to which oxidative stress plays a role in lameness and how dietary trace minerals help prevent it.

\section{Genes Related to Inflammation and Chemotaxis}

The proinflammatory cascade can be initiated via different pathways, and among them, the TLR are perhaps the most widely studied. The primary outcome of TLR activation is the synthesis of proinflammatory cytokines (e.g., TNF, IL1B, and IL6; De Nardo, 2015). The TLR can be activated via different pathogenassociated molecular patterns expressed on infectious agents. For example, lipopolysaccharide from gramnegative bacteria stimulates TLR4, and TLR2 is stimulated by lipoteichoic acid from gram-positive bacteria (De Nardo, 2015).

In the current study, the upregulation of $T L R 2$ with INO and upregulation of TLR 4 with AAC is indicative that hoof tissue in INO- and AAC-supplemented cows might have been subjected to different types of bacterial stimuli. Based on the upregulation of TNF and $I L 1 B$ in INO cows, it could be hypothesized that TLR2 activation in INO cows was more effective in mounting an inflammatory response than TLR4 activation in AAC cows. In contrast, the lack of agreement between TLR 4 and proinflammatory cytokine expression in AAC cows could reflect a downregulation of the TLR4 receptor by earlier LPS exposure (i.e., "endotoxin tolerance") or the possibility that the incorrect LPS ligand was present in AAC claws (Vatanen et al., 2016).

As a result of the concomitant upregulation of TLR2, $T N F$, and $I L 1 B$ in INO cows, their hoof tissue could have been under greater inflammatory stress, and this agrees with the systemic concentration of inflammatory biomarkers detected in INO compared with AAC cows (Batistel et al., 2016). The greater plasma concentration of IL-6 in INO cows (Batistel et al., 2016) is suggestive of a higher predisposition to lameness after parturition (Zhang et al., 2015).

\section{Transcription Factors}

The beneficial effects of peroxisome proliferatoractivated receptor (PPAR) in controlling expression of genes involved in lipid metabolism, anti-inflammatory response, and growth in ruminants have been reviewed recently (Bionaz et al., 2013). In the present study, the upregulation of PPARA and PPARD following supplementation of AAC suggests that greater bioavailability of trace minerals could directly or indirectly stimulate these transcription factors. The greater mRNA abundance of PPARA than PPARD or PPARG in hoof tissue (Osorio et al., 2012), indicated that expression of PPARA might be particularly important in corium tissue biology. Whether it stems from a role in lipid metabolism or inflammation remains to be determined.

\section{CONCLUSIONS}

Supplementing AAC during the peripartal period affected the transcription of a variety of genes that influence structure, oxidative stress, and inflammation status in the hoof. The overall greater mRNA abundance of KRT5 underscores the importance of this keratin and the greater need for tissue repair during the peripartal period. It remains to be discerned in future experiments whether the positive effects of AAC at a molecular level in the sole claw are reflective of lower subclinical development of sole ulcers, reduced disturbance in the dermal-epidermal homeostasis from heel erosion, or reduced incidence of other hoof diseases. Evaluating these phenotypic outcomes is important to give biological meaning to the transcriptomic alterations observed during peripartal AAC supplementation. It is conceivable that the PPAR play an important role in the biology of corium tissue, at least in terms of lipid metabolism and inflammation.

\section{ACKNOWLEDGMENTS}

Fernanda Batistel was supported in part by a $\mathrm{PhD}$ fellowship from Coordenação de Aperfeiçoamento de Pessoal de Nível Superior (CAPES) from the Brazilian Ministry of Education, and by Hatch funds under project ILLU-538-914, National Institute of Food and Agriculture (Washington, DC).

\section{REFERENCES}

Abuelo, A., J. Hernandez, J. L. Benedito, and C. Castillo. 2015. The importance of the oxidative status of dairy cattle in the periparturient period: Revisiting antioxidant supplementation. J. Anim. Physiol. Anim. Nutr. (Berl.) 99:1003-1016.

Arai, K. Y., A. Fujioka, R. Okamura, and T. Nishiyama. 2014. Stimulatory effect of fibroblast-derived prostaglandin E(2) on keratino- 
cyte stratification in the skin equivalent. Wound Repair Regen. 22:701-711.

Ballantine, H. T., M. T. Socha, D. J. Tomlinson, A. B. Johnson, A. S. Fielding, J. K. Shearer, and S. R. Van Amstel. 2002. Effects of feeding complexed zinc, manganese, copper, and cobalt to late gestation and lactating dairy cows on claw integrity, reproduction, and lactation performance. Prof. Anim. Sci. 18:211-218.

Batistel, F., J. S. Osorio, A. Ferrari, E. Trevisi, M. T. Socha, and J. J. Loor. 2016. Immunometabolic status during the peripartum period is enhanced with supplemental $\mathrm{Zn}, \mathrm{Mn}$, and $\mathrm{Cu}$ from amino acid complexes and Co from Co glucoheptonate. PLoS One 11:e0155804

Bergsten, C., P. R. Greenough, J. M. Gay, W. M. Seymour, and C. C. Gay. 2003. Effects of biotin supplementation on performance and claw lesions on a commercial dairy farm. J. Dairy Sci. 86:39533962.

Bionaz, M., S. Chen, M. J. Khan, and J. J. Loor. 2013. Functional role of PPARs in ruminants: Potential targets for fine-tuning metabolism during growth and lactation. PPAR Res. 2013:684159.

Boxman, I. L., C. Ruwhof, O. C. Boerman, C. W. Lowik, and M Ponec. 1996. Role of fibroblasts in the regulation of proinflammatory interleukin IL-1, IL-6 and IL-8 levels induced by keratinocytederived IL-1. Arch. Dermatol. Res. 288:391-398.

Cha, E., J. A. Hertl, D. Bar, and Y. T. Grohn. 2010. The cost of different types of lameness in dairy cows calculated by dynamic programming. Prev. Vet. Med. 97:1-8.

da Silva, L. A., L. G. Franco, I. B. Atayde, P. H. da Cunha, M. I. de Moura, and D. S. Goulart. 2010. Effect of biotin supplementation on claw horn growth in young, clinically healthy cattle. Can. Vet. J. 51:607-610.

De Nardo, D. 2015. Toll-like receptors: Activation, signalling and transcriptional modulation. Cytokine 74:181-189.

Dufour, A. 2015. Degradomics of matrix metalloproteinases in inflammatory diseases. Front. Biosci. (Schol. Ed.) 7:150-167.

Flower, F. C., and D. M. Weary. 2006. Effect of hoof pathologies on subjective assessments of dairy cow gait. J. Dairy Sci. 89:139-146.

Giudice, A., C. Arra, and M. C. Turco. 2010. Review of molecular mechanisms involved in the activation of the Nrf2-ARE signaling pathway by chemopreventive agents. Methods Mol. Biol. 647:3774 .

Hendry, K. A., A. J. MacCallum, C. H. Knight, and C. J. Wilde. 1997. Laminitis in the dairy cow: A cell biological approach. J. Dairy Res. 64:475-486.

Hendry, K. A., A. J. MacCallum, C. H. Knight, and C. J. Wilde. 2001. Synthesis and distribution of cytokeratins in healthy and ulcerated bovine claw epidermis. J. Dairy Res. 68:525-537.

Hennings, H., D. Michael, C. Cheng, P. Steinert, K. Holbrook, and S. H. Yuspa. 1980. Calcium regulation of growth and differentiation of mouse epidermal cells in culture. Cell 19:245-254.

Kansanen, E., S. M. Kuosmanen, H. Leinonen, and A. L. Levonen. 2013. The Keap1-Nrf2 pathway: Mechanisms of activation and dysregulation in cancer. Redox Biol. 1:45-49.

Karkoodi, K., M. Chamani, M. Beheshti, S. S. Mirghaffari, and A. Azarfar. 2012. Effect of organic zinc, manganese, copper, and selenium chelates on colostrum production and reproductive and lameness indices in adequately supplemented Holstein cows. Biol. Trace Elem. Res. 146:42-46.

Kellogg, D. W., D. J. Tomlinson, M. T. Socha, and A. B. Johnson. 2004. Review: Effects of zinc methionine complex on milk production and somatic cell count of dairy cows: Twelve-trial summary. Prof. Anim. Sci. 20:295-301.

Margaritelis, N. V., A. S. Veskoukis, V. Paschalis, I. S. Vrabas, K. Dipla, A. Zafeiridis, A. Kyparos, and M. G. Nikolaidis. 2015. Blood reflects tissue oxidative stress: A systematic review. Biomarkers 20:97-108.

Matés, J. M. 2000. Effects of antioxidant enzymes in the molecular control of reactive oxygen species toxicology. Toxicology 153:83104 .

Méhul, B., D. Bernard, and R. Schmidt. 2001. Calmodulin-like skin protein: A new marker of keratinocyte differentiation. J. Invest. Dermatol. 116:905-909.
Mülling, C. K., H. H. Bragulla, S. Reese, K. D. Budras, and W. Steinberg. 1999. How structures in bovine hoof epidermis are influenced by nutritional factors. Anat. Histol. Embryol. 28:103-108.

NRC. 2001. Nutrient Requirements of Dairy Cattle. 7th rev. ed. Natl. Acad. Press, Washington, DC.

Osorio, J. S., B. C. Fraser, D. E. Graugnard, S. S. Singh, J. K. Drackley, E. F. Garrett, and J. J. Loor. 2012. Corium tissue expression of genes associated with inflammation, oxidative stress, and keratin formation in relation to lameness in dairy cows. J. Dairy Sci. 95:6388-6396.

Osorio, J. S., E. Trevisi, C. Li, J. K. Drackley, M. T. Socha, and J. J. Loor. 2016. Supplementing Zn, Mn, and Cu from amino acid complexes and Co from cobalt glucoheptonate during the peripartal period benefits postpartal cow performance and blood neutrophil function. J. Dairy Sci. 99:1868-1883.

Pillay, Y., A. Phulukdaree, S. Nagiah, and A. A. Chuturgoon. 2015 Patulin triggers NRF2-mediated survival mechanisms in kidney cells. Toxicon 99:1-5.

Rabiee, A. R., I. J. Lean, M. A. Stevenson, and M. T. Socha. 2010. Effects of feeding organic trace minerals on milk production and reproductive performance in lactating dairy cows: A meta-analysis. J. Dairy Sci. 93:4239-4251.

Shearer, J. K., M. L. Stock, S. R. Van Amstel, and J. F. Coetzee. 2013. Assessment and management of pain associated with lameness in cattle. Vet. Clin. North Am. Food Anim. Pract. 29:135-156.

Siciliano-Jones, J. L., M. T. Socha, D. J. Tomlinson, and J. M. DeFrain. 2008. Effect of trace mineral source on lactation performance, claw integrity, and fertility of dairy cattle. J. Dairy Sci. 91:1985-1995.

Tomlinson, D. J., C. H. Mulling, and T. M. Fakler. 2004. Invited review: Formation of keratins in the bovine claw: Roles of hormones, minerals, and vitamins in functional claw integrity. J. Dairy Sci. 87:797-809.

Vandesompele, J., K. De Preter, F. Pattyn, B. Poppe, N. Van Roy, A. De Paepe, and F. Speleman. 2002. Accurate normalization of real-time quantitative RT-PCR data by geometric averaging of multiple internal control genes. Genome Biol. 3:RESEARCH0034.

Vatanen, T., A. D. Kostic, E. d'Hennezel, H. Siljander, E. A. Franzosa, M. Yassour, R. Kolde, H. Vlamakis, T. D. Arthur, A. M. Hämäläinen, A. Peet, V. Tillmann, R. Uibo, S. Mokurov, N. Dorshakova, J. Ilonen, S. M. Virtanen, S. J. Szabo, J. A. Porter, H. Lähdesmäki, C. Huttenhower, D. Gevers, T. W. Cullen, M. Knip, and R. J. Xavier. 2016. Variation in microbiome LPS immunogenicity contributes to autoimmunity in humans. Cell 165:842-853.

Vermunt, J. J., and P. R. Greenough. 1996. Sole haemorrhages in dairy heifers managed under different underfoot and environmental conditions. Br. Vet. J. 152:57-73.

Waelti, E. R., S. P. Inaebnit, H. P. Rast, T. Hunziker, A. Limat, L. R. Braathen, and U. Wiesmann. 1992. Co-culture of human keratinocytes on post-mitotic human dermal fibroblast feeder cells: Production of large amounts of interleukin 6. J. Invest. Dermatol. 98:805-808.

Wang, F., Y. Li, Y. Cao, and C. Li. 2015. Zinc might prevent heatinduced hepatic injury by activating the Nrf2-antioxidant in mice. Biol. Trace Elem. Res. 165:86-95.

Weiss, W. P., and C. A. Zimmerly. 2000. Effects of biotin on metabolism and milk yield of dairy cows. Pages $22-30$ in Proc. $62 \mathrm{nd}$ Cornell Nutr. Conf. for Feed Manuf. Cornell Univ., Ithaca, NY.

Zhang, G., D. Hailemariam, E. Dervishi, Q. Deng, S. A. Goldansaz, S. M. Dunn, and B. N. Ametaj. 2015. Alterations of innate immunity reactants in transition dairy cows before clinical signs of lameness. Animals (Basel) 5:717-747.

Zhao, X. J., Z. P. Li, J. H. Wang, X. M. Xing, Z. Y. Wang, L. Wang, and Z. H. Wang. 2015a. Effects of chelated $\mathrm{Zn} / \mathrm{Cu} / \mathrm{Mn}$ on redox status, immune responses and hoof health in lactating Holstein cows. J. Vet. Sci. 16:439-446.

Zhao, X. J., X. Y. Wang, J. H. Wang, Z. Y. Wang, L. Wang, and Z. H. Wang. 2015b. Oxidative stress and imbalance of mineral metabolism contribute to lameness in dairy cows. Biol. Trace Elem. Res. 164:43-49. 